\title{
REPRESENTACIÓN DE REDES Y PROSOPOGRAFÍA: EL CASO DEL I CONDE DE TORENO Y LA FAMILIA QUEIPO DE LLANO
}

\author{
Pelayo Fernández García* \\ Universidad DE Oviedo
}

\begin{abstract}
RESUMEN
Álvaro Queipo de Llano y Bernaldo de Quirós (1599-1662) alcanzó la nobleza de título como conde de Toreno tras una larga carrera al servicio de la Corona. El estudio de su correspondencia lo demuestra, pero también destaca el entramado familiar de los Queipo de Llano. Este artículo busca, a partir de su contexto histórico y familiar, dar testimonio de cómo la evolución de un proyecto inicialmente reducido a un solo individuo y su familia puede extenderse de forma natural a una investigación de redes sociales de mayor envergadura, e intenta señalarse la utilidad y los límites de la representación gráfica de un estudio egocentrado.
\end{abstract}

PALABRAS CLAVES: Toreno, siglo XVII, Queipo de Llano, redes sociales, UCINET

*pelayo.fer.gar@gmail.com 


\title{
NETWORK REPRESENTATION AND PROSOPOGRAPHY: THE CASE OF THE I COUNT OF TORENO AND HIS FAMILY, THE QUEIPO DE LLANO
}

\author{
Pelayo Fernández García* \\ University of Oviedo
}

\begin{abstract}
Álvaro Queipo de Llano and Bernaldo de Quirós (1599-1662) reached the nobility, as first count of Toreno, at the end of a long career serving the Crown. The study of its correspondence shows in detail this service, but, at the same time, it also highlights Queipo de Llano's family framework. This paper will try to testify, from this historical and family context, how the evolution of a project originally centered on a single individual and its family, can naturally extends to a larger social network research. It also tries to point out the usefulness of the graphic representation of an egocentrated study, and the limits of its application.
\end{abstract}

KEYWORDS: Toreno, 17th century, Queipo de Llano, social network, UCINET 


\section{INTRODUCCIÓN}

La metodología de redes sociales no es un fin en sí mismo, sino una herramienta que puede ayudarnos a comprender las relaciones interpersonales y la articulación familiar en la sociedad tradicional. La dicotomía entre familia e individuo, en una época en el que este no ha asumido plenamente su papel de actor social, es dúctil y flexible ${ }^{1}$, pero precisamente en este sentido el estudio de redes nos presenta una perspectiva única a través de la que analizar dos objetos: el familiar y el individual, el linaje que aúpa a un individuo y aquel que eleva en condición social a su linaje, en el entramado sociopolítico de los Queipo de Llano y la trayectoria y camino personal de don Álvaro hasta la nobleza.

Don Álvaro Queipo de Llano y Bernaldo de Quirós (1599-1662) alcanzó la nobleza de título como primer conde de Toreno tras una larga carrera al servicio de la Corona. Había ejercido no solo como corregidor en Granada, Madrid y Málaga, sino también como supernumerario del Consejo y Contaduría Mayor de Hacienda, en unos tiempos convulsos de crisis para la monarquía hispánica, donde España debía hacer frente a guerras extra e intrapeninsulares, con una necesidad cada vez más acuciante de hombres y dinero para hacer frente a estos conflictos ${ }^{2}$. El volumen de su correspondencia, consecuencia directa de sus múltiples responsabilidades a lo largo de su cursus honorum, llevó a delimitar originalmente la atención tan solo sobre aquellos corresponsales con vínculos familiares con don Álvaro.

Con el software UCINET, esta correspondencia permitió dar lugar a las primeras variaciones de redes egocentradas sobre el mismo. Una red egocentrada es la representación estilizada de un conjunto de relaciones entre actores sociales, que tiene como centro a un personaje específico. Por supuesto, ninguna red de este tipo está completa, puesto que en todos los casos existen relaciones interpersonales que escapan a su percepción, pero de todos modos proporciona una visión de conjunto del capital relacional del sujeto de estudio ${ }^{3}$. El análisis de redes sociales ha sido utilizado generalmente por la historiografía sociopolítica, aunque sin llegar a la profundidad de la antropología y la sociología ${ }^{4}$. Este artículo solo significa una muestra del potencial de esta metodología, y

1. F. CHACón JiMÉNEZ (2011), 387-388.

2. P. Fernández García (2018), 71-80. J. Barrientos Grandon.

3. J. M. Imízcoz Beunza (2009), 100.

4. F. Chacón Jiménez (2011), 386-381. 
de los resultados que pueden obtenerse al integrar en nuestra disciplina la profundidad metodológica de otras afines.

Grosso modo, el objetivo de este artículo es, partiendo de la trayectoria de una investigación así, proporcionar un ejemplo de los límites y desafíos que supone un proyecto de estas características, y sus posibles soluciones. Esto no solo significa confrontar los problemas metodológicos que plantea, sino los propios límites de su objeto de estudio. Una investigación egocentrada más limitada puede evolucionar a un estudio más complejo con relativa facilidad, según las circunstancias. Se espera que desgranar el proceso de esta investigación específica pueda servir como ejemplo para afrontar el comienzo de una nueva investigación relacional, y cómo el estudio de un individuo puede extenderse más allá de su trayectoria de vida, incluyendo una perspectiva más amplia de su entorno familiar y social.

\section{BREVES APUNTES HISTÓRICOS E HISTORIOGRÁFICOS}

Desde el comienzo de la Edad Moderna, la corte se convertiría en el medio más importante para integrar a la nobleza en el juego político de la monarquía, asegurándose su lealtad y centralizando distintas redes territoriales. Se fomentaba la competencia por captar los recursos políticos de la monarquía, y la obtención de gracias de aquellos mejor conectados al monarca y los poderosos. De esta forma ascendían social, política y económicamente no solo aquellos establecidos en la jerarquía cortesana, sino parientes, aliados y clientes promocionados como intermediarios entre la corte y las élites locales y regionales, a través de cortes, cabildos o relaciones personales. Los regidores municipales fueron fundamentales para obtener recursos para las guerras, y el patronazgo real tuvo bien en cuenta sus esfuerzos de integrar a las ciudades en torno a su propio sistema político. Los corregidores eran agentes directos del rey en las ciudades, y principales mediadores en un sistema donde el patronazgo tradicional no era suficiente para mantener la fluidez de gobierno que requería la monarquía. A ellos el rey concedía sus favores, incluyendo nuevos cargos y títulos de nobleza 5 . Este proceso de expansión del poder regio hacia la periferia territorial, permitía al monarca gobernar con intermediarios de confianza, moldeando en el proceso las lealtades mediante la redistribución de puestos, privilegios $y$ honores conectados con el poder central ${ }^{6}$. Vinculado a ello se encuentra

5. J. M. Imízcoz Beunza (2016), 35-40.

6. J. M. Imizcoz Beunza y A. Artola Renedo (2016), 10-12. 
también la noción del ideal de perpetuación y estrategias familiares dirigidas a la reproducción o movilidad social. En este contexto, se considera un orden estamental no rígido, e incluso aún menos dentro de la nobleza (ya fuese de título, mediana o hidalga) ${ }^{7}$. Dentro de él, y en un esfuerzo de proyección de la familia de los Queipo, más allá de sus esferas de poder tradicionales y construyendo relaciones en otros ámbitos, especialmente la corona ${ }^{8}$, se inserta la evolución personal del primer conde de Toreno.

La prosopografía o la biografía colectiva como metodología de historia social para estudiar la administración fue presentada por Lawrence Stone en 1971 como "la investigación de las características más comunes de un grupo de actores históricos, a través del estudio colectivo de sus vidas", y se adaptó en España sin contradicciones en paralelo a la Escuela de Annales. El rumbo de esta historia social de la administración fue inicialmente dirigido por Pere Molas, quien trabajó en mor de un estudio de las instituciones que incluía la biografía colectiva de quienes las ocuparon, pero también analizando las características comunes de sectores sociales, y buscando los mecanismos mediante los cuales se habían erigido en élites de poder. Esta perspectiva metodológica ha sido la que más ha pervivido en el tiempo a su iniciador, aunque sin distanciarse demasiado de este ${ }^{10}$.

Más recientemente, la prosopografía se ha combinado con el estudio de las redes sociales, lo que permite ampliar el conocimiento más allá de los límites del grupo, a través de las dinámicas sociales de sus individuos. Por ejemplo, en el estudio de las élites se extiende a los lazos de patronazgo e influencia de las oligarquías, más allá de una institución o territorio concreto, a través de los lazos personales de los individuos, lo que permite identificar redes de poder entre la corte y las provincias, por ejemplo, o dinámicas de crecimiento de familias periféricas a través de actividades al servicio al Estado lejos de su territorio de origen, a través de distintos ámbitos ${ }^{11}$. Las relaciones sociales de los sujetos iban condicionadas no solo por el núcleo consanguíneo más próximo, sino también por el parentesco más extenso, aunque no anulándose completamente como actor social, con la posibilidad de cada persona para establecer conexiones propias que definiesen su propia red. Autores como Jean Pierre Dedieu, José María Imízcoz, Michel Beltrand

7. A. J. Felani Pintos (2019), 66-67 y 79-80.

8. A. Carrasco Martínez (2016), 83-84.

9. L. Stone (1971), 46.

10. J. Martínez Millán (1996), 87-88.

11. J. M. Imízcoz Beunza (2009), 83-86.

(C) Baetica. Estudios Historia Moderna y Contemporánea, 40, 2020, 99-119. Facultad de Filosofia y Letras, Universidad de Málaga. Departamento de Historia Moderna y Contemporánea 
o Caro Baroja, entre otros, han iniciado una evolución de los estudios sobre las élites siguiendo "círculos concéntricos" y extendiendo estos sobre las alianzas matrimoniales, parentescos, amistades, y relaciones clientelares ${ }^{12}$.

En los últimos años, aunque la homogeneidad se mantenga, influencias de otras disciplinas como la sociología y la antropología han permitido que el individuo cobre una mayor importancia. De esta forma, las relaciones de patronazgo y clientelismo son enfocadas no solo en los lazos horizontales sino también los verticales, y dejan de circunscribirse tan solo a colectivos uniformes. La tendencia actual es un análisis de redes con terminología, categorías y métodos de trabajo propios de la sociología, y una clara influencia de la teoría de grafos. Se distingue además entre el análisis de redes sociales y la metodología de redes clientelares, centrándose esta última en el ejercicio de la gracia y favor del monarca a través de relaciones interpersonales encadenadas ${ }^{13}$.

\section{PRIMEROS PASOS}

La escritura epistolar ha adquirido un gran interés para los investigadores, presentándose a las redes epistolares como una fuente extremadamente valiosa para realizar un examen cualitativo de los nexos sociales de un individuo y reconstruir una red egocentrada en torno a él. La bibliografía ha probado la necesidad de estas colecciones documentales para comprender los vínculos sociales a todos los niveles, y se considera que una buena red epistolar permitía a la nobleza bien posicionada mantener sus lazos personales con la corte, administrar su patrimonio y gestionar sus conexiones más allá de su alcance geográfico y el trato cara a cara ${ }^{14}$.

Inicialmente, y en tanto que se quería experimentar con la metodología de análisis de redes, se pensó en utilizar como base la correspondencia de la Casa de Meres, en lugar de los fondos procedentes de la familia Queipo de Llano. La razón para este cambio fue la misma que llevó a escoger al primer conde de Toreno y no a sus sucesores: es decir, el volumen documental a disposición del investigador, en el primer caso por escasez, y en el de los otros condes de Toreno, por exceso.

El estudio de redes sociales contempla una explotación epistolar intensiva, por lo que se requiere la correspondencia completa de un indi-

12. A. J. Felani Pintos (2019), 67-68.

13. Ibidem, 59-64.

14. Ibidem, 76-77. 
viduo con el conjunto de sus corresponsales para percibir debidamente la red egocentrada del que recibe las cartas (más allá de las limitaciones de aquellos con quienes no se relaciona por carta), y la carencia de la propia correspondencia que emitía (que generalmente se conserva solo de forma esporádica en borradores $)^{15}$. La primera aproximación al estudio del primer conde de Toreno se realizó sobre lo que se creía era un corpus documental completo, compuesto por 442 cartas, cronológicamente localizadas entre 1635 y 1662 , y procedentes de 133 corresponsales distintos ${ }^{16}$. Dentro de él, se realizó un estudio inicial (presentado en un congreso en 2013) centrado únicamente en la familia de sangre ( 81 cartas, 17 corresponsales) y política (58 cartas, 15 corresponsales), dando lugar a las siguientes gráficas ${ }^{17}$ :

\section{Gráfica 1. I conde de Toreno: familia de sangre $\mathbf{I}^{18}$}

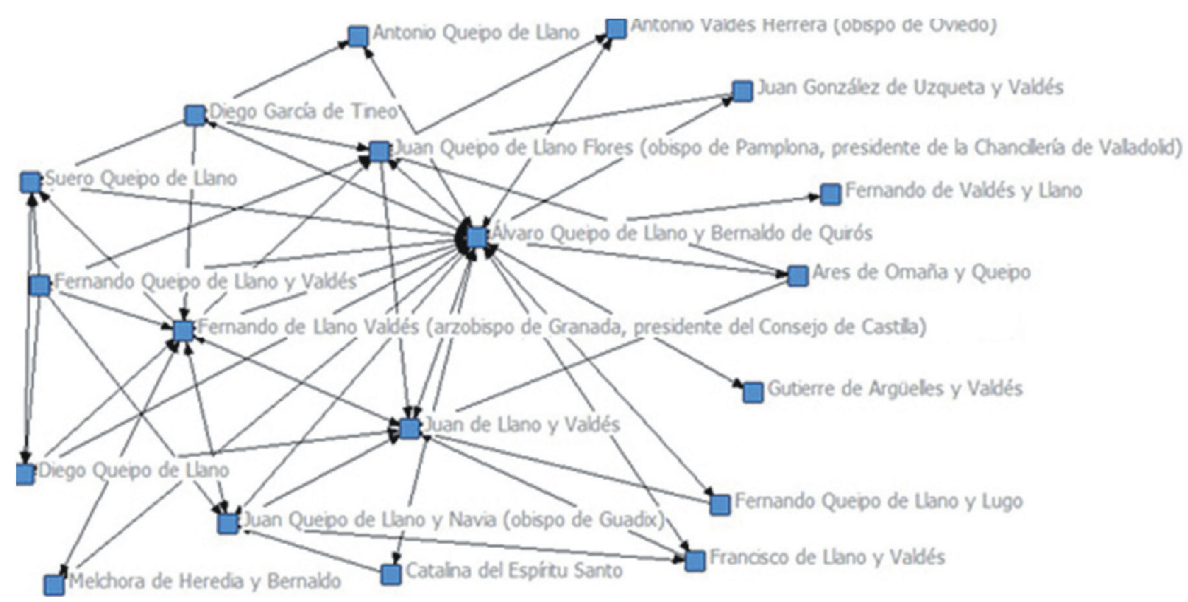

En función de esta primera gráfica, podemos observar de forma visualmente sencilla cómo, al margen de la situación central del propio don Álvaro (núcleo egocentrado de la misma) en ella destaca su tío, Fernando de Llano Valdés, que aglutina un gran número de interacciones y contactos por su posición predominante como presidente del Consejo de Castilla. El

15. J. M. Imízcoz Beunza (2009), 102-103.

16. Archivo Histórico de la Universidad de Oviedo (AHUO), Archivo de los condes de Toreno (ACT), correspondencia del primer conde de Toreno, cajas 1-2.

17. P. Fernández García (2017), 159-160.

18. Ibidem, 165 . 
resto de individuos son claramente identificables en torno a los apellidos Queipo, Llano, y Valdés, con contadas excepciones que pueden explicarse por cambios de nombre que sin embargo ocultan una relación familiar como familia de sangre.

Gráfica 2. I conde de Toreno: familia política II $^{19}$

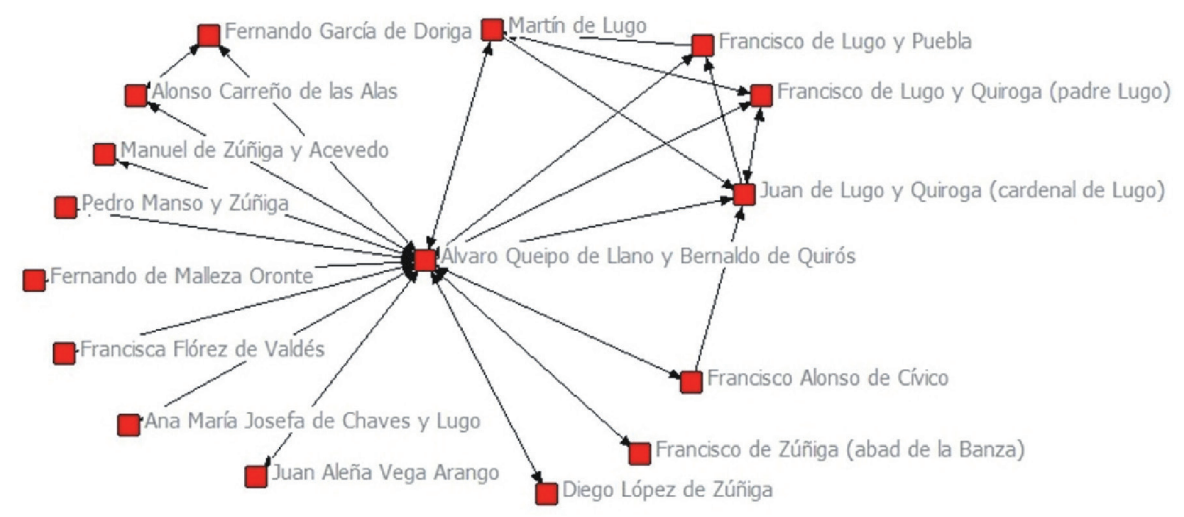

La segunda gráfica, de tamaño más reducido, apenas muestra interacciones notables, exceptuando un pequeño grupo de parientes a través del primer matrimonio del conde. Sin embargo, sirve también para ejemplificar una funcionalidad simple del programa $\mathrm{UCINET}^{20}$, el de modificar los colores de los nodos, algo especialmente útil para diferenciar tipologías de los individuos, como puede verse en la gráfica 3, que combina familia de sangre con familia política, a una escala que aún permite ver con facilidad sus interrelaciones:

19. Ibidem, 166.

20. Para la correcta utilización de este programa, se recomienda la consulta del libro de J. Paniagua López (2012). 


\section{Gráfica 3. I conde de Toreno: familia $\mathbf{I}^{21}$}

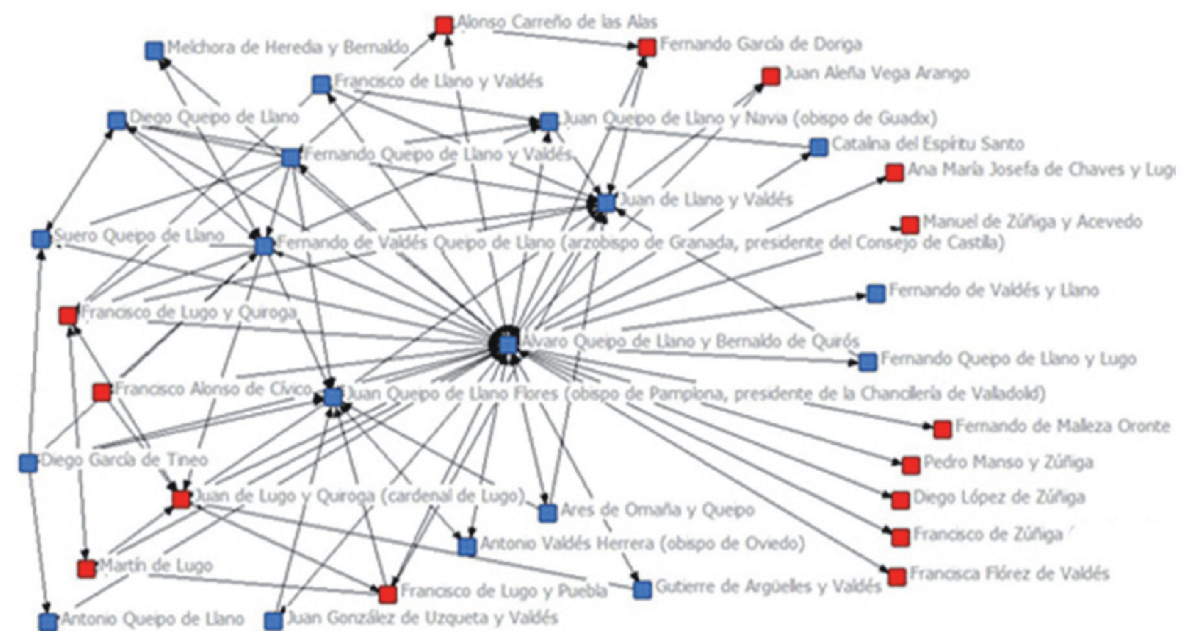

Sin embargo, durante diversas reorganizaciones del Archivo Histórico de la Universidad de Oviedo apareció nueva correspondencia que obligó a reformular los gráficos para incluir un mayor número de información ${ }^{22}$. El último análisis egocentrado sobre las relaciones familiares del primer conde de Toreno partía de un total de 711 cartas entre 203 corresponsales $^{23}$, y específicamente sobre 269 cartas y 48 escribientes (29 de ellos y 201 cartas con relación de sangre con el conde, y 20 individuos y 65 cartas de su familia política ${ }^{24}$. Esta aparición de nueva correspondencia supuso que la primera aproximación de redes de este sujeto quedase obsoleta unos años después, pero no debe considerarse la primera iteración como un esfuerzo vano, en tanto que su evolución sirvió para tantear los límites de la representación gráfica egocentrada, al intentar abarcar un mayor número de individuos.

21. P. Fernández García (2017), 166.

22. Ibidem, 159. AHUO, ACT, correspondencia del primer conde de Toreno, caja 3.

23. AHUO, ACT, correspondencia del primer conde de Toreno, cajas 1-3.

24. P. Fernández García (2018), 53-69, 54. 


\section{Gráfica 4. I conde de Toreno: familia de sangre II $^{25}$}

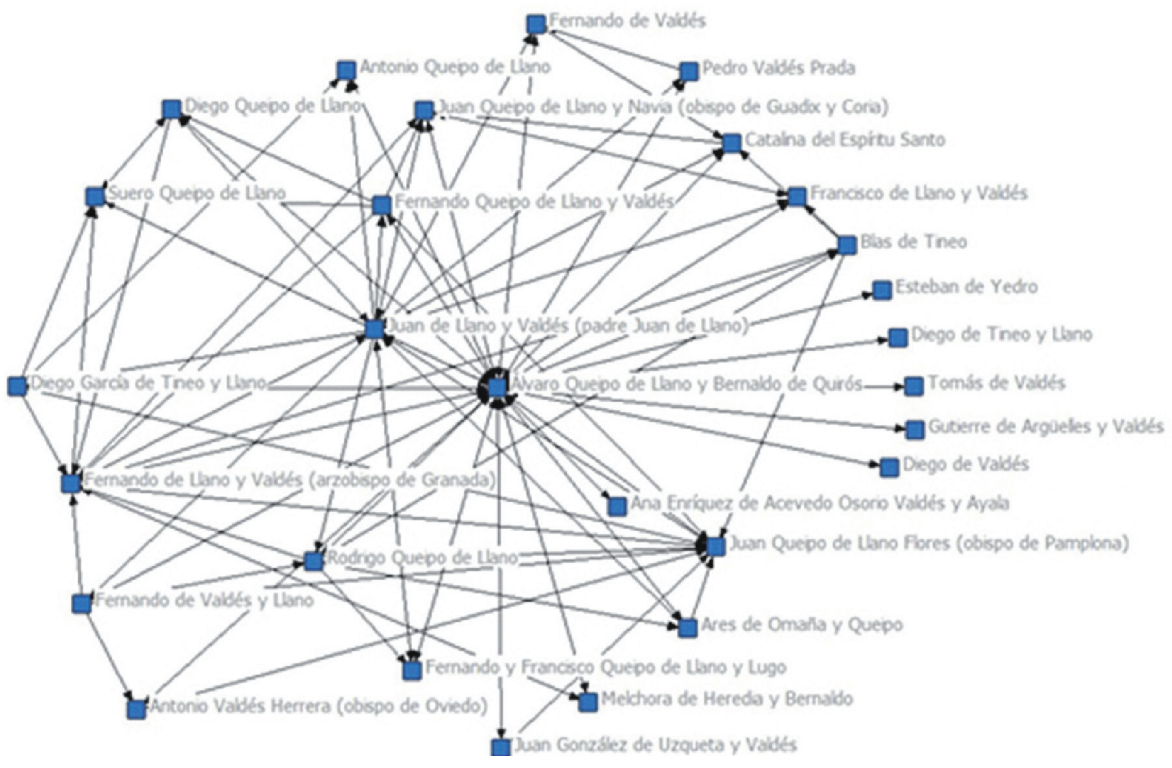

Gráfica 5. I conde de Toreno: familia política II $^{26}$

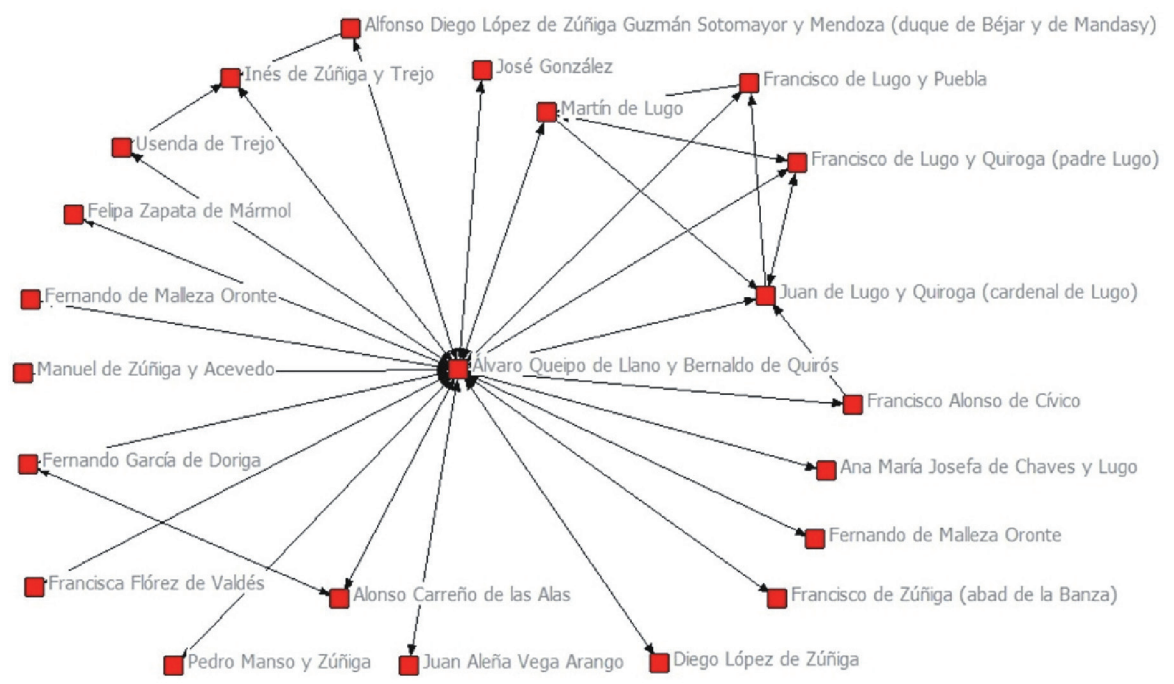

25. Ibidem, 62.

26. Ibidem, 63.

(C) Baetica. Estudios Historia Moderna y Contemporánea, 40, 2020, 99-119.

Facultad de Filosofía y Letras, Universidad de Málaga. Departamento de Historia Moderna y Contemporánea 
De esta forma podemos ver cómo, si en las anteriores gráficas aumentaba la densidad a niveles apreciables, pero resultando aún cómodos para su lectura, cuando las gráficas 4 y 5 se aúnan en una nueva que combina, una vez más, la familia de sangre y la política, se crea un totum revolutum (gráfica 6) difícilmente interpretable, por la excesiva densidad de nodos. Esto invita al investigador a hacerse consciente de que un número excesivo de protagonistas puede volver inútil una representación gráfica egocentrada, quizás haciendo necesario simplificar esta eliminando individuos que únicamente se relacionan con el núcleo de la misma.

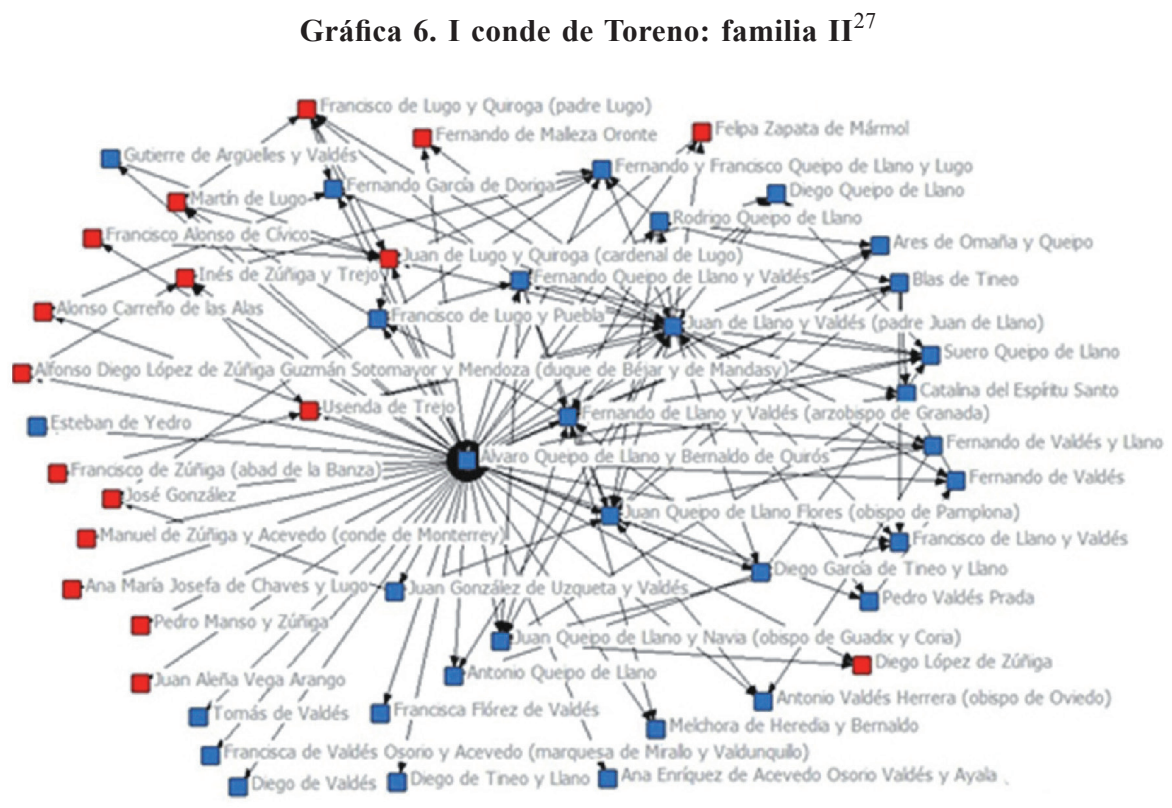

\section{REDEFINICIÓN: NUEVOS HORIZONTES}

El ejemplo de la familia Queipo de Llano durante el segundo tercio del siglo XVII no solo sirve para mostrar la construcción de una red al servicio de la familia por parte de determinados individuos, sino también para proporcionar una mirada privilegiada a sus relaciones internas, y cómo y hasta qué punto sus preocupaciones individuales podían insertarse en estrategias grupales dirigidas a la reproducción y promoción de la familia a

27. Ibidem, 64. 
muy distintos niveles, locales, regionales, nacionales, e incluso en algunos casos supraestatales.

Sin embargo, existen muchos más puntos de interés más allá de este prisma particular. La transcripción y examen de la correspondencia familiar del conde permitió subrayar la influencia no tanto de don Álvaro sino también de su entramado familiar en el entorno político y religioso de su época $^{28}$. A comienzos del siglo XVII, los Queipo de Llano mantuvieron a varios de sus integrantes ostentando puestos políticos y religiosos de consideración, en un ejemplo temprano (antes de regularizarse con la llegada de la dinastía borbónica) de un linaje periférico elevándose a nuevas cotas de poder más allá de su ámbito regional.

El nepotismo no es, stricto sensu, una forma de patronazgo, pero en todo caso el poderoso beneficia al pariente por la fuerza de la sangre, y no necesariamente por los beneficios mutuos que pudiesen obtener por la protección, promoción, prestigio social o gracia que el poderoso concediese. Todos ellos pueden presentarse dentro del fenómeno del patronazgo y el clientelaje, pero desde otras dinámicas. Los obispos no dejan de ser importantes autoridades locales, auxiliares del poder del rey, con participación directa en la vida política local ${ }^{29}$; la presencia y expansión de los Queipo de Llano en los obispados no deja de ser una ampliación de su poder a nivel peninsular, favorecida por los lazos de sangre.

En este contexto, debido a que el Archivo Histórico de la Universidad de Oviedo no solo conservaba correspondencia del primer conde, sino también una pequeña cantidad (38 cartas entre 30 distintos corresponsales) de Juan Queipo de Llano y Navia, obispo de Guadix y primo del I conde ${ }^{30}$, se decidió combinar ambas fuentes documentales para buscar vínculos comunes, ganando una nueva perspectiva de la influencia política y religiosa de la familia. La muestra total de esta nueva investigación sumaba, incluyendo a don Álvaro y a su primo, 113 cartas y 19 corresponsales, dando lugar a reconstrucciones egocentradas dobles ${ }^{31}$. 
Gráfica 7. I conde de Toreno: red relacional eclesiástica en torno a los Queipo de Llano ${ }^{32}$

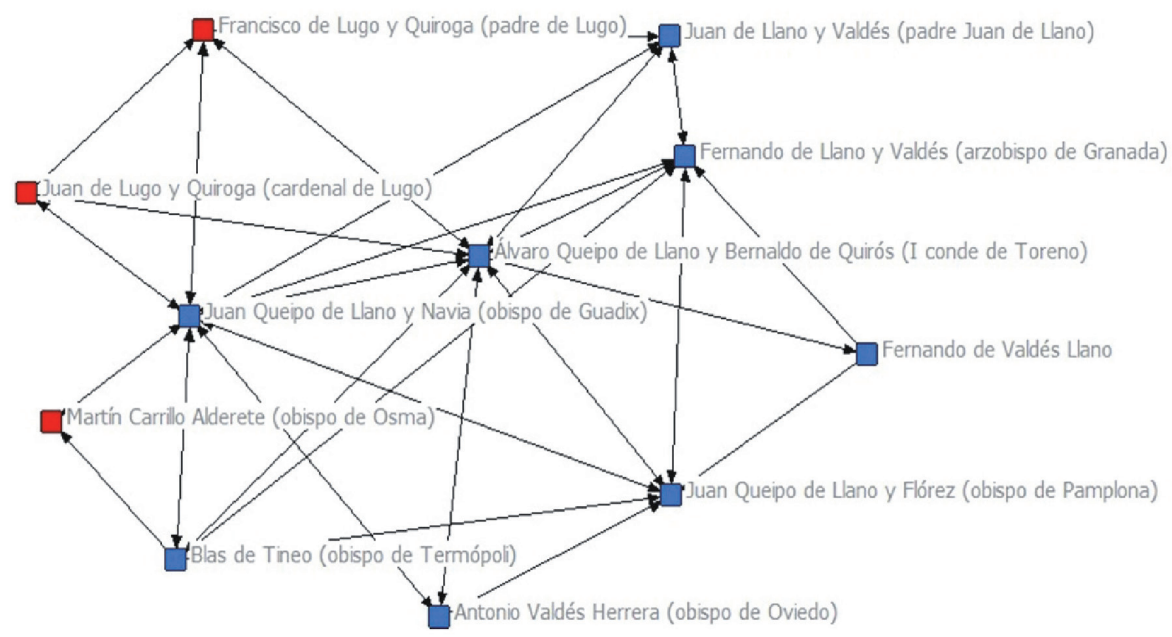

Gráfica 8. I conde de Toreno: red relacional laica entre Álvaro y Juan Queipo de Llano y Navia ${ }^{33}$

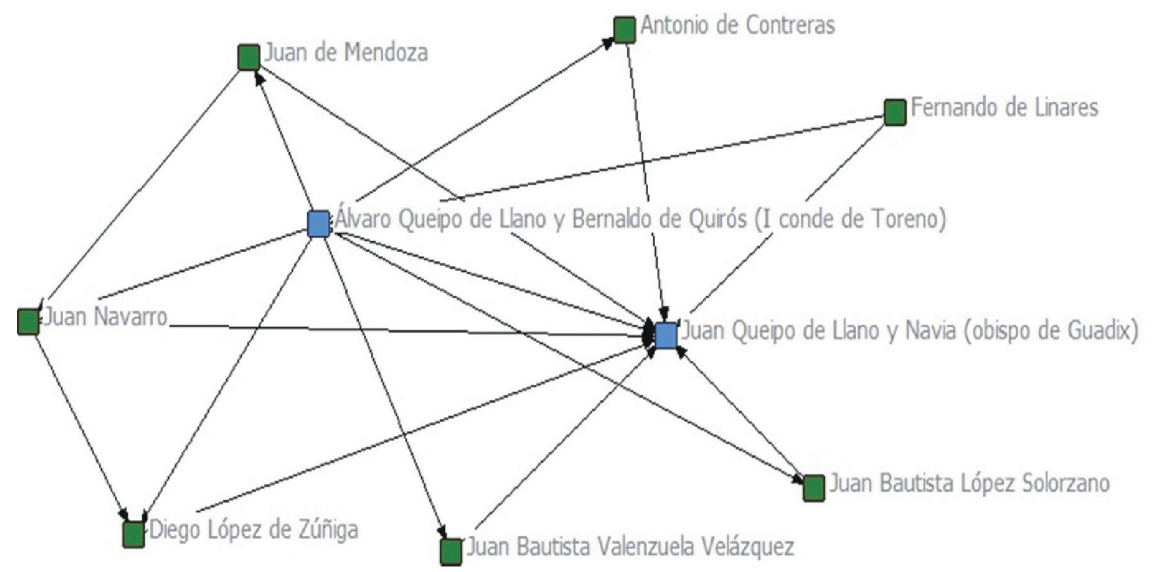

De las gráficas 7 y 8 , puede traslucirse una base similar a los primeros análisis familiares. Los nodos en azul son los contactos eclesiásticos entre

32. Ibidem, 1343.

33. Ibidem, 1345.

(C) Baetica. Estudios Historia Moderna y Contemporánea, 40, 2020, 99-119. Facultad de Filosofia y Letras, Universidad de Málaga. Departamento de Historia Moderna y Contemporánea 
los dos protagonistas del estudio, y que poseen en mayor o menor medida una relación de sangre con los Queipo de Llano; los rojos son contactos eclesiásticos ajenos a la familia, si bien cabe señalar que los dos Lugo coinciden al mismo tiempo con familia política, como parientes de la primera mujer de don Álvaro. El obispo de Osma es el primer individuo completamente nuevo con lo expuesto a los estudios previos, proveniente de la correspondencia del obispo de Guadix. No será el único, puesto que los nodos verdes traen consigo un puñado de individuos laicos, contactos comunes entre Álvaro y Juan Queipo de Llano. La combinación de todos ellos culmina en la gráfica 9, que nos permite mostrar mejor la extensión de las influencias de los Queipo de Llano, sin basarse únicamente en la perspectiva del primer conde de Toreno.

Gráfica 9. I conde de Toreno: contactos eclesiásticos y laicos entre Álvaro y Juan Queipo de Llano ${ }^{34}$

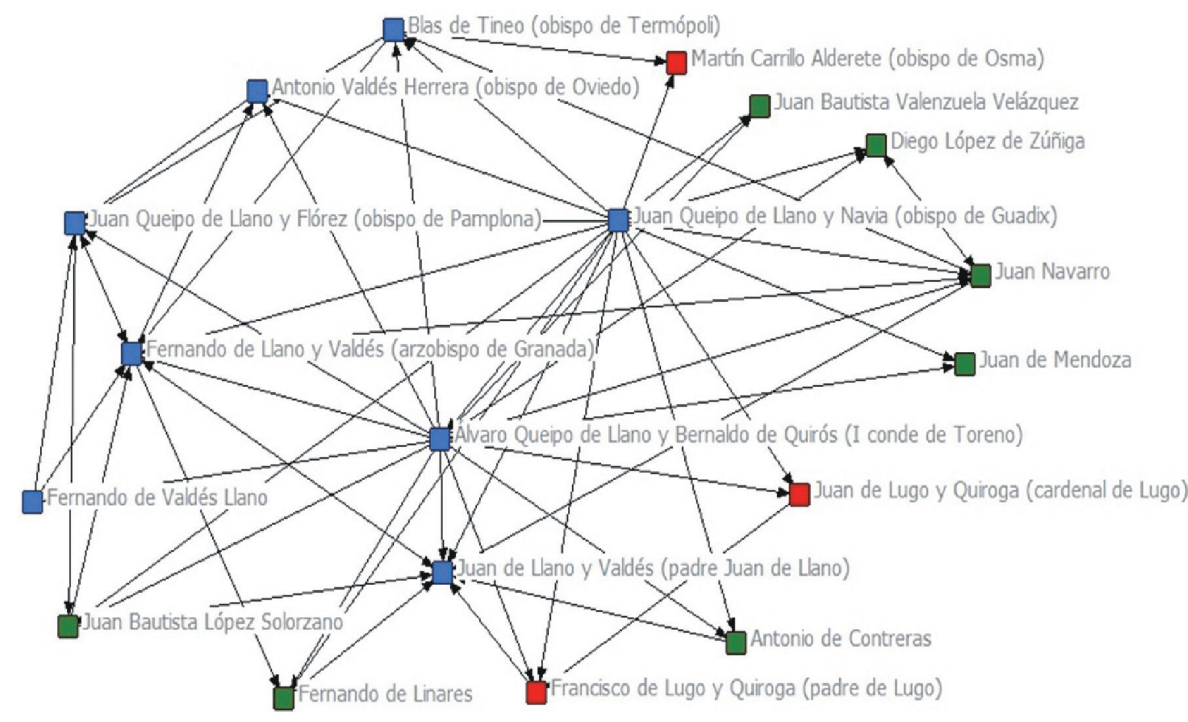

La continuación del estudio de este desde la perspectiva de la logística militar trajo consigo unas miras más amplias, nacidas no solo de una base documental más extensa, sino también de objetivos más ambiciosos, que exploraban el capital relacional de don Álvaro no reducido a su entramado 
familiar. En el proceso, surgieron determinadas preguntas con respecto a cómo representar gráficamente nuevas categorizaciones de los individuos. ¿Cómo mostrar de forma simple el contenido de las cartas de un corresponsal, la intensidad de su comunicación, o el grado de interconexión de determinados nodos? Las respuestas tomaron forma en las siguientes gráficas, en su día publicadas a toda página, debido a su densidad:

\section{Gráfica 10. I conde de Toreno: variables temáticas ${ }^{35}$}

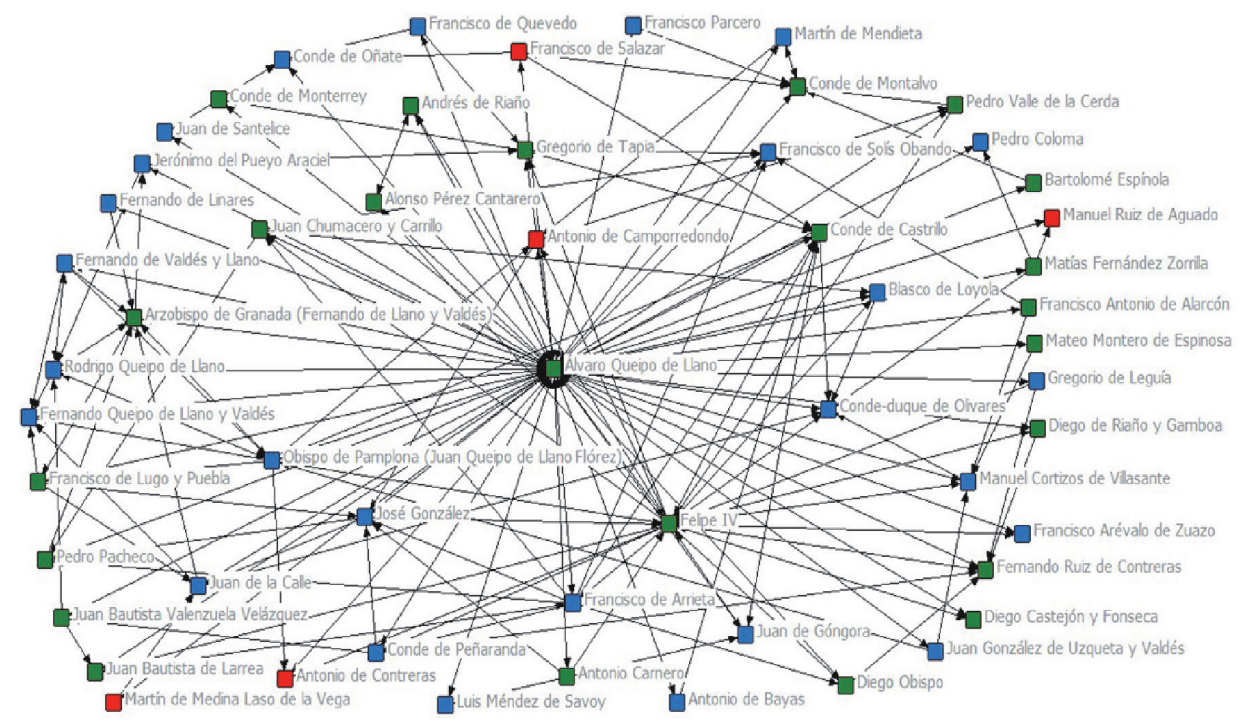

La gráfica 10 muestra simplemente, utilizando de nuevo la funcionalidad de cambio de color de los nodos, una diversidad temática en el intercambio de correspondencia: los individuos en azul únicamente trataron con don Álvaro temas militares, y aquellos en rojo tan solo temas económicos; los señalados en verde hablaron sobre ambos temas. La gráfica 11, a continuación, vuelve a utilizar el cambio de colores, esta vez para identificar los nodos principales de la gráfica. Normalmente, el lector debería ser capaz de identificarlos en función de una mayor acumulación de líneas conectoras, pero con una alta densidad de nodos, un código de color reintensifica la facilidad para interpretar visualmente la misma.

35. P. Fernández García (2018), 107. 
Gráfica 11. I conde de Toreno: variables por nodos principales ${ }^{36}$

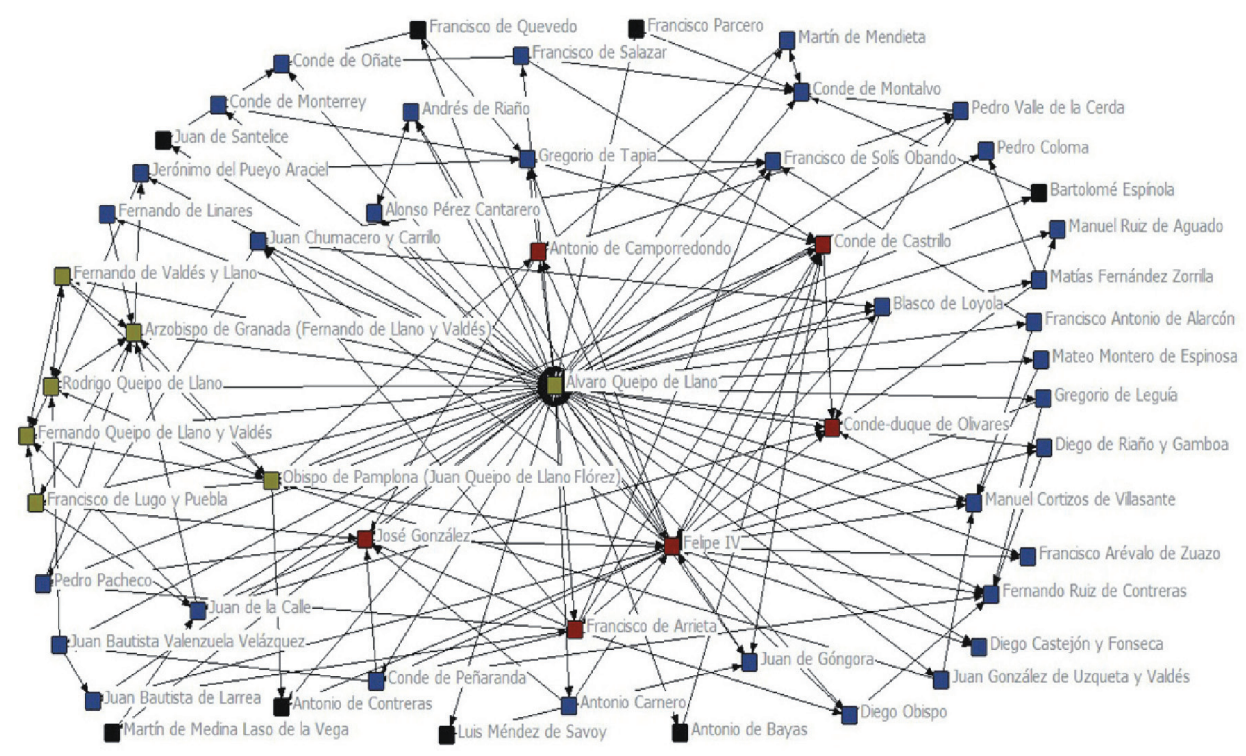

Las gráficas 11 y 12 comparten, además, una pequeña modificación dirigida a evitar que características ajenas a temas de logística militar y económica falseen la interpretación de la gráfica. Por ello, como don Álvaro, su familia aparece marcada en color dorado, en tanto que su mayor intensidad e interconexión con el conde son mayores por vínculo familiar. Respecto al resto del esquema de colores, también lo comparten ambos: el color negro representa a los individuos con menor número de interacciones, el granate el de mayor número, y el azul un término medio. La última gráfica aprovecha la capacidad de UCINET para cambiar la forma de los nodos, y así presentar al mismo tiempo el número de interacciones con colores, y la intensidad de las mismas (el número de cartas con respecto a don Álvaro) a través de la forma: los triángulos representan el menor número de cartas, el hexágono el mayor, y el cuadrado el término medio.

36. Ibidem, 108. 


\section{Gráfica 12. I conde de Toreno: variables por nodos principales} e interacciones $^{37}$

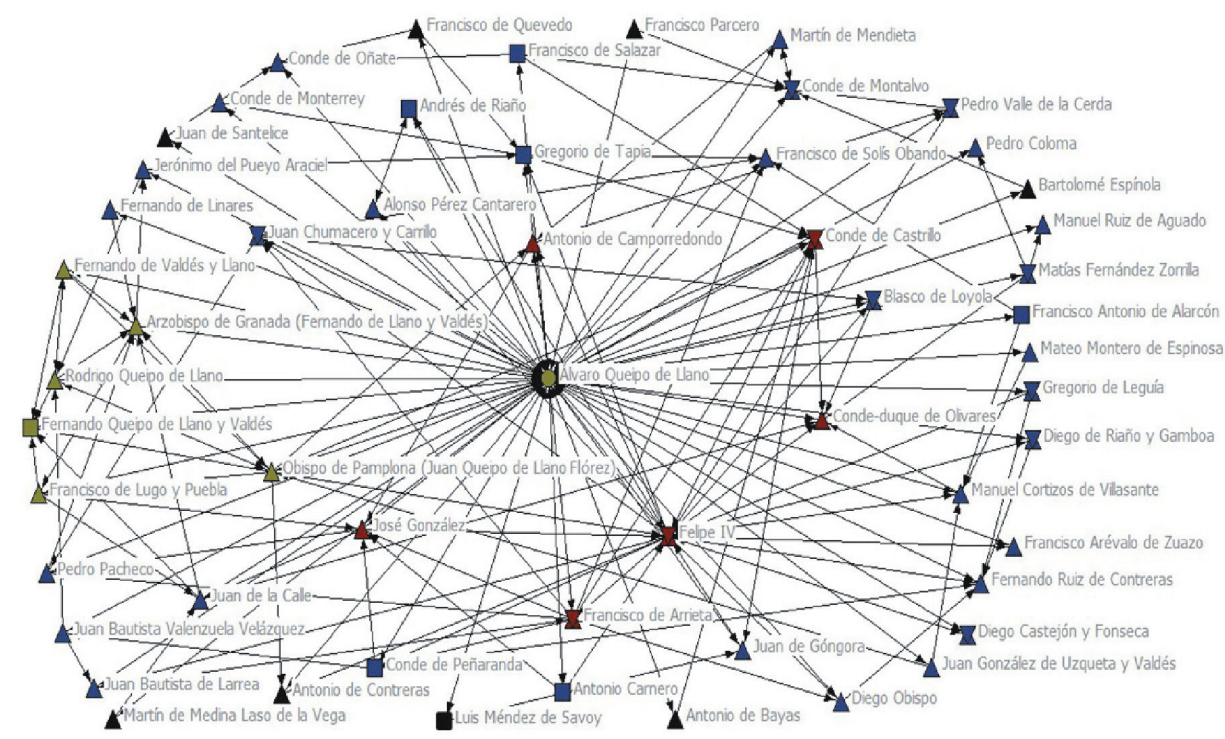

\section{FRONTERAS Y NUEVOS HORIZONTES DE LA METODOLOGÍA DE REDES}

A través del estudio de la correspondencia del primer conde, se ha obtenido información suya y de su familia. Los límites entre ambos no se desdibujan, pero se entrelazan: los ámbitos de influencia de la familia Queipo de Llano se encuentran firmemente imbricados a los del conde. El análisis de redes permite la observación del cambio histórico desde nuevas perspectivas mucho menos impersonales ${ }^{38}$; en el caso de los Queipo de Llano, viendo cómo las dinámicas familiares se intrincan con su servicio a la Corona, y la promoción de distintos individuos y de su linaje. Si bien la perspectiva egocentrada de la investigación proporciona una "gravedad temática" que hasta cierto punto deforma su perspectiva, por ser sus relaciones el centro de la información, precisamente el desarrollo de su red de relaciones permite entender aquellas desde una perspectiva más amplia

37. Ibidem, 110.

38. J. M. Imízcoz Beunza (2011), 396. 
que la que une al primer conde y su familia, demarcando las influencias extrafamiliares de este grupo de individuos.

Además, si la prosopografía se caracteriza por el estudio de un colectivo a través del conocimiento detallado del conjunto de sus componentes, a través del estudio de la correspondencia la prosopografía relacional aumenta enormemente las posibilidades de comprender mejor a dicho colectivo ${ }^{39}$, al igual que el estudio de las relaciones de un individuo potencialmente permite obtener nuevos datos sobre su biografía. Aunque resulta insuficiente para conocer los nexos personales construidos por un individuo, la prosopografía fija rasgos comunes en un grupo, y podría servir como referencia y complemento para el análisis de estos a través de otros métodos. El análisis de redes sociales permite a su vez mostrar de forma muy gráfica y esquemática la red de estos nexos ${ }^{40}$.

La movilidad de las sociedades en la época moderna se basaba en gran medida en la creación de redes y conexiones sociales que a su vez dan forma a cargos, mercedes, honores y privilegios que impulsan y refuerzan el potencial de un linaje y los individuos asociados a él. La familia no se cierra en torno al patrimonio de la casa, sino que se extiende a la ampliación de oportunidades por miembros. Generalmente, las oligarquías de la segunda mitad del siglo XVI y la primera mitad del XVII ascendían a la nobleza de título por una doble vía, a través del servicio a instituciones políticas o religiosas, y mediante el sistema clientelar que toma forma durante el desarrollo de tal servicio, a menudo ejerciendo como intermediadores entre los poderes a los que sirven y realidades más específicas, locales o regionales ${ }^{41}$. Este proceso, debe señalarse de nuevo, ejemplifica a la perfección los Queipo de Llano, y en especial durante el periodo que lleva a la concesión del título de conde de Toreno para don Álvaro.

En lo que respecta a la utilización de gráficos para visualizar estas redes relacionales, está demostrado empíricamente cómo una buena representación gráfica de la información (de interés, con ideas complejas, y presentando muchas ideas en poco espacio de forma multivariada), permite el conocimiento visual si goza de una calidad suficiente ${ }^{42}$. En el extremo opuesto, hemos podido ver cómo una excesiva densidad en las gráficas dificulta la lectura, y demasiada concentración de nodos reduce su utilidad. Existen

39. J. M. Imízcoz Beunza (2017), 28-29.

40. A. J. Felani Pintos (2019), 82-83.

41. F. Chacón JimÉnez (2011), 340-342, 385.

42. H. Trujillo, F. M. Mañas y J. González Cabrera (2010), 70. 
distintas soluciones a este inconveniente (más allá de una presentación a mayor tamaño), centradas en compartimentar la realidad de los análisis. Algunos ejemplos podrían ser perspectivas de análisis únicamente desde nuevos contextos temáticos (de forma similar a la gráfica 10), añadir características cualitativas a las diferentes relaciones (quizás añadiendo diversidad de color y/grosor en las líneas que unen a los sujetos), o sumar coordenadas temporales a una serie de gráficas relacionales, añadiendo una perspectiva evolutiva, que permitiría ver el desarrollo de redes de nuestro sujeto de estudio. Y todo ello partiendo únicamente desde una base sencilla y centrada más en lo visual y en la comunicación más simple con el lector.

Las gráficas presentadas aquí permiten apreciar visualmente los núcleos relacionales más importantes, a partir de los que se pueden estudiar la prevalencia de responsabilidades, funciones, o intercambios entre los Queipo de Llano, don Álvaro y estos. El estudio de su capital relacional a través de la correspondencia ha permitido identificar diferentes individuos posicionados en puntos capitales de la administración hispánica (obispados, consejos, juntas...), que hilvanan entre sí una nutrida red de contactos e influencias de los que se nutre don Álvaro y los suyos para medrar en su carrera. A través de los nexos y los puntos más importantes que señala la gráfica, se pueden identificar aquellos individuos más importantes o con mayor relación con don Álvaro, lo que actúa como un semáforo de atención al estudio de relaciones específicas, y que permite así identificar los servicios que condujeron el ascenso a la nobleza de título (fundamentalmente su colaboración en la logística para obtener recursos demográficos y económicos para las necesidades bélicas de la monarquía) ${ }^{43}$.

Sin embargo, las funcionalidades de UCINET van mucho más allá, y pueden ser utilizadas para reforzar subgrupos dentro del conjunto de la gráfica, marcar distintos atributos, o adaptar gráficamente métricas en función de los datos que le transmitan. A través de los instrumentos de representación gráfica, el investigador puede dar forma y comparar la estructura de varias redes y la posición de los individuos en ellas, con parámetros como su composición (el tipo de lazos que unen a sus sujetos), la frecuencia (el número de interacciones en un periodo determinado), o la durabilidad (el periodo de vigencia efectiva de cada relación $)^{44}$. Las perspectivas de estudio para este tipo de representaciones gráficas en las redes sociales son muy amplias, y su auténtico potencial aún está por explorar.

43. P. Fernández García (2018), 100-104 y 274-277.

44. J. M. Imízcoz Beunza (2009), 100. 


\section{BIBLIOGRAFÍA}

Barrientos Grandon, Javier, “Álvaro Queipo de Llano y Valdés”, en Diccionario biográfico electrónico, Real Academia de la Historia. URL: <http://dbe.rah. es/biografias/76433/alvaro-queipo-de-llano-y-valdes>

Carrasco Martínez, Adolfo (2016), "Redes de patronazgo y clientela señoriales en la Edad Moderna. Una reflexión”, en J. M. Imízcoz Beunza y A. Artola Renedo (coords.), Patronazgo y clientelismo en la monarquía hispánica (siglos XVI-XIX), Universidad del País Vasco, Bilbao, pp. 75-85.

Chacón Jiménez, Francisco (2011), "Familias, sociedad y sistema social. Siglos XVI-XIX”, en F. Chacón Jiménez y J. Bestard Comas (coords.), Familias: historia de la sociedad española (del final de la Edad Media a nuestros días), Cátedra, Madrid, pp. 325-392.

Felani Pintos, Alberto Juan (2019), "Las relaciones de patronazgo y clientelismo en la Monarquía Hispánica: un estado de la cuestión", Tiempos Modernos, 9, 38, pp. 59-70.

Fernández García, Pelayo (2017), "El conde de Toreno. Estrategias familiares y redes sociales", en J. F. Henarejos López y A. Irigoyen López (eds.), Escenarios de familia: trayectorias, estrategias y pautas culturales, siglos $X V I-X X$, Universidad, Murcia, pp. 159-170.

- (2018), "La familia Queipo de Llano: auge y desarrollo en la época del I conde de Toreno", en F. Chacón Jiménez, A. Esteve Palós y R. Cicerchia (eds.), Construyendo identidades y analizando desigualdades. Familias y trayectorias de vida como objeto de análisis en Europa y América Siglos XVI-XXI, Centre d'Estudis Demogràfics, Barcelona, pp. 53-69.

- (2018), "La familia Queipo de Llano. Religión e influencia en la primera mitad del siglo XVII", en E. Serrano Martín y G. Pérez (eds.), Poder, sociedad, religión y tolerancia en el mundo hispánico, de Fernando el Católico al siglo XVIII, Institución Fernando el Católico, Zaragoza, pp. 1337-1352.

- (2018), El I conde de Toreno: logística y economía de guerra en la crisis de la monarquía hispánica, Ministerio de Defensa, Madrid.

Imízcoz Beunza, José María y Artola Renedo, Andoni (2016), "Vínculos verticales, entramado social y lealtad política. Reflexiones a modo de presentación", en J. M. Imízcoz Beunza y A. Artola Renedo (coords.), Patronazgo y clientelismo en la monarquía hispánica (siglos XVI-XIX), Universidad del País Vasco, Bilbao, pp. 9-15.

Imízcoz Beunza, José María (2009), "Las redes sociales de las élites: conceptos, fuentes y aplicaciones", en E. Soria Mesa, J. J. Bravo Caro, J. M. Delgado Barrado, F. Chacón Jiménez y J. Bestard Comas (coords.), Las élites en la época moderna la monarquía española, vol. 1, Universidad, Córdoba, pp. 77-112. 
- (2011), "Las redes de la monarquía: Familias y redes sociales en la construcción de España”, en F. Chacón Jiménez y J. Bestard Comas (coords.), Familias: historia de la sociedad española (del final de la Edad Media a nuestros dias), Cátedra, Madrid, pp. 393-444.

- (2016), "Las relaciones de patronazgo y clientelismo: declinaciones de la desigualdad social”, en J. M. Imízcoz Beunza y A. Artola Renedo (coords.), Patronazgo y clientelismo en la monarquía hispánica (siglos XVI-XIX), Universidad del País Vasco, Bilbao, pp. 19-42.

- (2017), “Actores de procesos de cambio. Reflexiones metodológicas desde el "análisis relacional"”, en M. T. NAvA RodríGuEz (coord.), De ilustrados a patriotas: Individuo y cambio histórico en la Monarquía española, Sílex, Madrid, pp. 19-40.

Irigoyen López, Antonio (2016), "El patronazgo de los obispos en la España moderna", en J. M. Imízcoz Beunza y A. Artola Renedo (coords.), Patronazgo y clientelismo en la monarquía hispánica (siglos XVI-XIX), Universidad del País Vasco, Bilbao, pp. 135-150.

Martínez Millán, José (1996), "Las investigaciones sobre patronazgo y clientelismo en la administración de la monarquía hispana durante la Edad Moderna", Studia Historica. Historia Moderna, 15, pp. 83-106.

Paniagua López, Julián (2012), Curso de análisis de redes sociales. Metodología y estudios de caso, Universidad de Granada, Granada.

Stone, Lawrence (1971), "Prosopography", Daedalus, 100, 1, pp. 46-79.

Trujillo, Humberto; Mañas, Fernando M. y González Cabrera, Joaquín (2010), "Evaluación de la potencia explicativa de los grafos de redes sociales clandestinas con UciNet y NetDraw", Universitas Psychologica, 9, 1, pp. 67-78. 